
Wagner

\title{
5 The Digital Exploration of Maya Hieroglyphic Writing and Language
}

\begin{abstract}
The Maya hieroglyphic script (300 BCE-1500 CE), which has only been partially deciphered, is one of the most significant writing traditions of the ancient world. In 2014, the project Text Database and Dictionary of Classic Mayan ${ }^{1}$ was established at the University of Bonn by the North Rhine-Westphalian Academy of Sciences, Humanities and Arts and the Union of the German Academies of Sciences and Humanities, to research the written language of the pre-Columbian Maya. The project aims to use digital methods and technologies to compile the epigraphic contents and object histories of all known hieroglyphic texts. Based on these data, a dictionary of the Classic Mayan language will be compiled and published near the end of the project's runtime in 2028. The project is methodologically situated in the digital humanities and conducted in cooperation with the Göttingen State and University Library (Grube \& Prager, 2016).
\end{abstract}

Keywords: Maya hieroglyphic writing, digital epigraphy, virtual research environment, lexicography, XML/TEI

\subsection{Introduction}

The subject of our research project is the written language of the Classic Maya, whose cultural area extended over the territory of the present-day nation states of Mexico, Guatemala, Belize and Honduras (Figure 5.1). Maya writing was used for more than 1,500 years and can be found, for example, on free-standing monuments (stelae, altars), architectural elements (lintels, columns, door jambs), portable objects and in the natural environment, such as in caves or on rock faces (Grube, 2001). It has

1 Textdatenbank und Wörterbuch des Klassischen Maya [http://mayawoerterbuch.de/].

Christian Prager, Nikolai Grube, Katja Diederichs, Sven Gronemeyer, Elisabeth Wagner, Rheinische Friedrich-Wilhelms-Universität, Bonn

Maximilian Brodhun, Franziska Diehr, Niedersächsische Staats- und Universitätsbibliothek, Göttingen Sven Gronemeyer, La Trobe University, Melbourne 
survived on more than 10,000 text-bearing objects, dating between 300 BCE and $1500 \mathrm{CE}$ and originating from more than 500 archaeological sites. The glottographic writing system comprises about 1,000 figurative graphs, most of which are signs for words or syllables. They represent figurative and abstract objects from the natural environment and material culture, human and animal body parts, heads of humans and animals or portraits of supernaturals, among other forms.

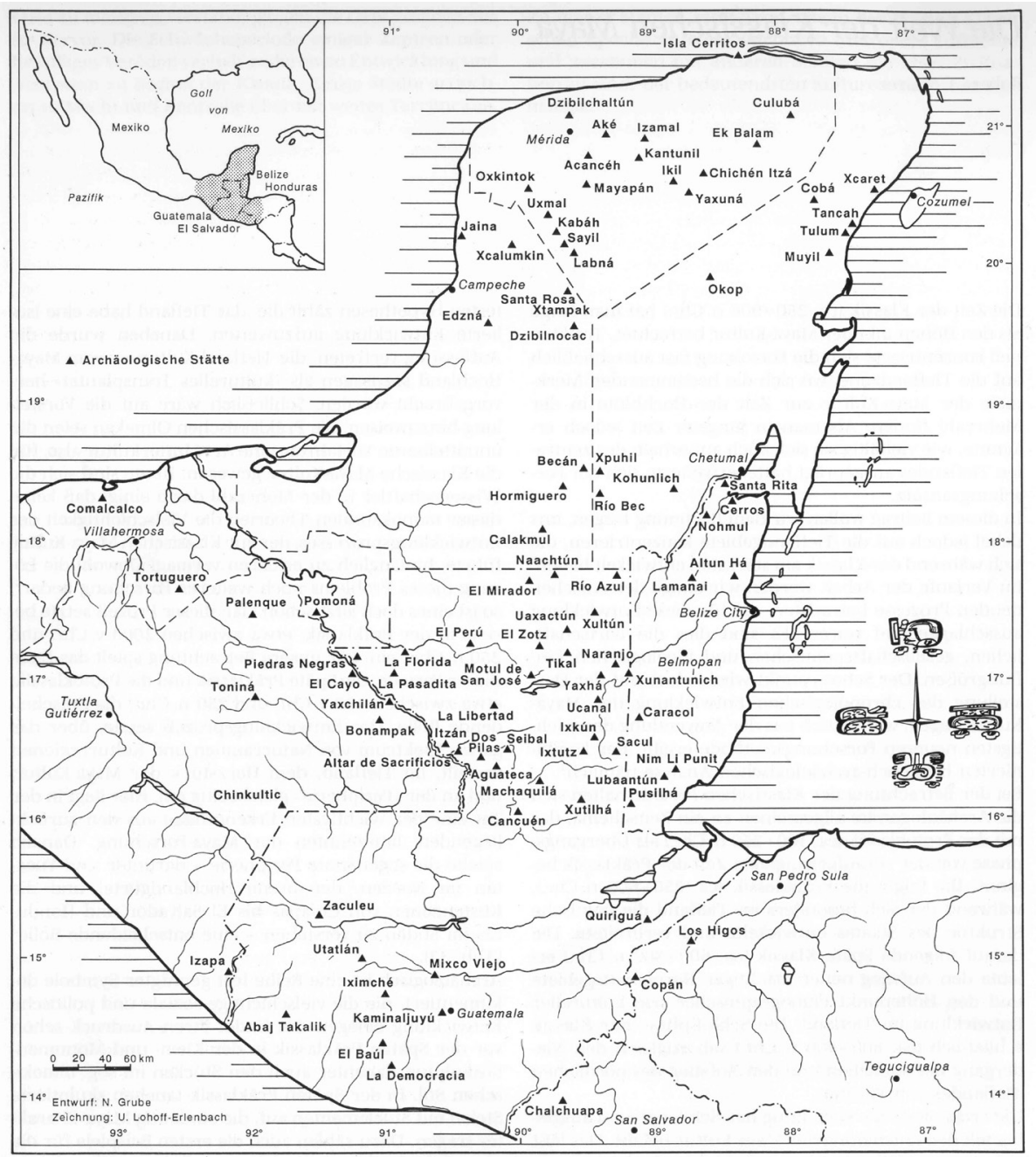

Figure 5.1: Map of the Yucatan peninsula with major archaeological sites (drawing by N. Grube and U. Lohoff-Erlenbach) 
The language of the hieroglyphs, now called Classic Mayan, has been preserved in large part in colonial and modern Ch'olan and Yukatekan languages (Wichmann, 2006, p. 201). Many texts display calendar dates that record the exact sequence of events, providing unique data on the history of Maya writing and language. Classic Mayan can thus be reconstructed with chronological precision, and the results can be compared with findings from historical linguistics.

Many inscriptions originate from in or around the palaces of divine kings who ruled over independent city-states. The inscriptions often contain biographical information on political elites and provide written evidence for inter- and intradynastic connections between the ruling families.

Some public monuments, like Stela D from Pusilha (Figure 5.2), describe actions such as war or royal visits. Others attest to ceremonies and religious rituals carried out in the context of accessions to the throne, ancestor worship, calendrical anniversaries, inaugurations, processions and other occasions that marked royal daily life (Martin \& Grube, 2008).

\subsection{Maya Hieroglyphic Writing}

The Maya writing system is considered a hieroglyphic script because of the iconic character of its approximately constituent 1,000 graphs. Typologically, it is a logosyllabic, or rather, a morphographic writing system with two basic, functional sign types: syllabic signs and morphographs. The latter denote concrete words and bound morphemes, whereas the former represent vowels and open syllables and thus permit the syllabic spelling of lexical and grammatical morphemes. In addition, syllabic signs were used as pre- or post-fixed phonetic complements for morphographs. Thus, it was possible to write words entirely with syllabic signs or by simply using morphographs.

Usually, however, morphographs and syllabographs were combined to form morpho-syllabic spellings of words (Figure 5.3). A high level of calligraphic complexity was further achieved through allographic notation and modification of graph shapes. More common syllables could be written with at least two or more graphs, which explains the extremely high number of syllabic signs (about 300) relative to the total inventory of more or less 1,000 graphemes in the Maya script (Grube, 1994). This phenomenon allowed scribes to compose aesthetically ambitious texts that minimized sign repetition.

The signs were combined into roughly quadratic blocks (Figure 5.4), not unlike Korean Hangul. A single hieroglyphic block usually corresponds to the emic concept of a Classic Mayan word. In most texts, these blocks were arranged in double columns that were read from left to right and from top to bottom. Sentences were formed by sequencing hieroglyphic blocks to reflect various syntactic features, such as possession. Multiple sentences were joined to produce complex texts, whose syntax and discourse structure are comparable to those found in modern Mayan languages. 


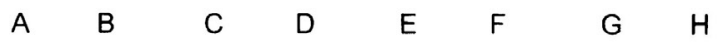

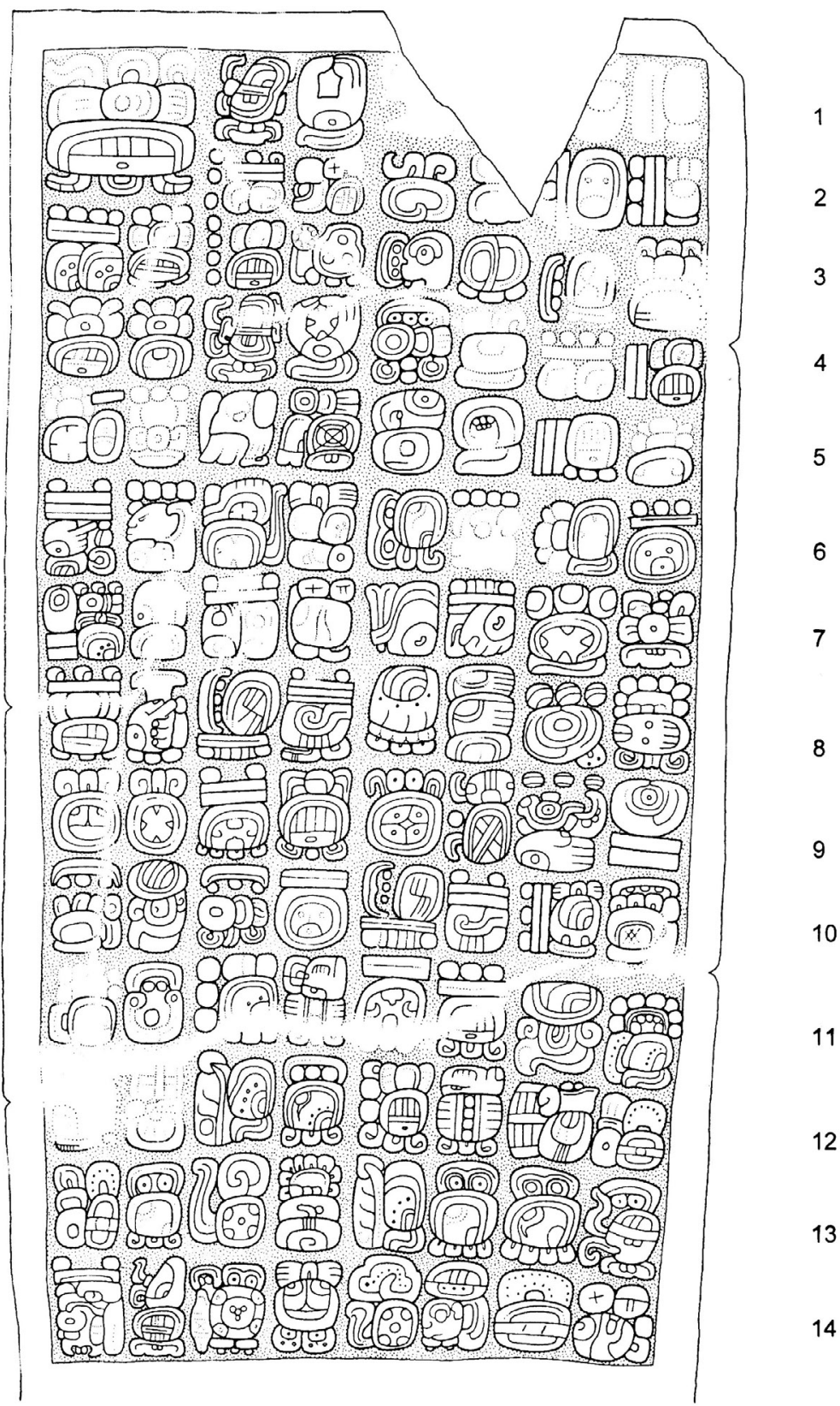

Figure 5.2: Stela D from the Maya site of Pusilha, Belize, with references to local dynastic and political history (drawing by C. Prager) 
bahlam „jaguar“

morphemic

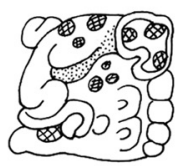

BALAM syllabic

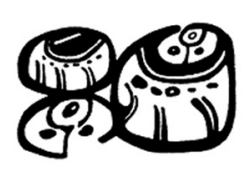

ba-la-ma

morpho-syllabic

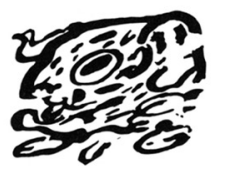

BALAM-ma

Figure 5.3: Examples of basic sign functions in Maya writing (concept by C. Prager)

The individual elements within each hieroglyphic block are traditionally subdivided into main and small graphs; main graphs are spatially larger and approximately square in shape, whereas small graphs are attached to the periphery of the main characters and oriented along their vertical or horizontal axis. Within a block, individual graphs could be arranged side-by-side or on top of each other (affixation). They could also merge into a single graph (conflation). In addition, two or more graphs could partially or completely overlap (ligature), or one could be inserted into the other (infixation). Altering the shape of an individual graph or block had no influence on its pronunciation or meaning.

Graph morphology and the arrangement of glyphs into blocks are particularly challenging for epigraphers to interpret in those cases in which either all, or some, of the signs have not yet been deciphered, or have only been hypothetically deciphered and thus elude linguistic verification. Documenting the original spelling or graph arrangement using XML/TEI is therefore essential to epigraphic work with syllabic and morpho-syllabic hieroglyphic writing systems, since a simple, linear transcription of a text does not show original spellings or placement of the glyphs within the block (Prager \& Gronemeyer, 2016). 


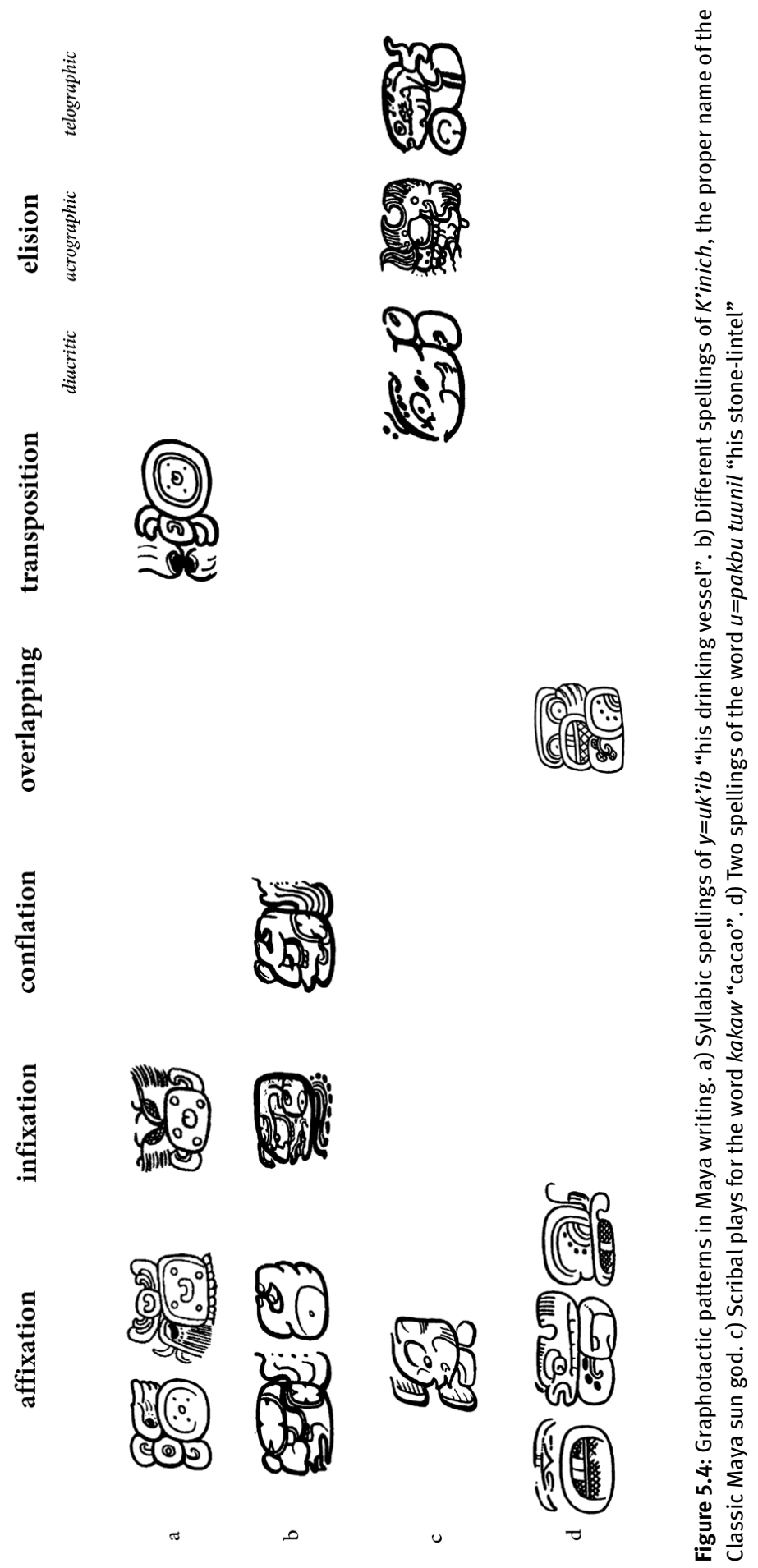


The aforementioned graphemic and graphotactic strategies affected only the graphic realization of words in the Maya script. The principle of underrepresenting specific word-endings, in contrast, impacted both visual form and pronunciation of the hieroglyphs. Omission through underrepresentation enabled scribes to graphically vary individual words and texts. This scribal practice also had an impact on the Classic Mayan lexicon, because underrepresenting phonemes in writing elicits different pronunciations of a given word, which have to be considered and examined in the context of this dictionary project. Using this wide range of graphemic and graphotactic strategies, Maya scribes were able to create a wide variety of texts that avoided repeating the same graphs or spellings. This technique suggests that these artists sought to maximize visual splendor and designed texts and pictorial works as individual pieces, even though their contents are often rather formulaic and stereotypical (Zender, 1999).

\subsubsection{Decipherment}

Considerable breakthroughs have already been achieved in the decipherment of the Classic Mayan written language (Houston \& Martin, 2016). However, despite the great progress made in recent decades, some $30 \%$ of the script's 1,000 signs remain unreadable, even today. One reason is their lack of systematic attestation. Even in cases in which individual signs are legible, texts may still elude understanding because the Classic Mayan language itself has not survived; instead, it can only be reconstructed through historical linguistic comparison of the 30-odd Mayan languages that have been documented since European conquest, most of which are still spoken today (Wichmann, 2006). However, much pre-Hispanic Mayan vocabulary has been lost in the aftermath of European colonization. Consequently, comprehensive documentation and decipherment of the approximately 10,000 extant hieroglyphic texts, reconstruction of the language that they record, and documentation of that language in a dictionary, are necessary to acquire a deeper understanding of Classic Maya culture, history, religion and society.

Recent research on Maya writing and language has addressed material form and alternative reading hypotheses for graphemes with varying degrees of plausibility, as well as vague semantic interpretations of hieroglyphs and text passages. For many graphemes, multiple readings have been proposed whose plausibility we evaluate by means of propositional logic based on individual arguments for decipherment that have been published in the literature. In this manner, we can qualify proposed readings and decipherments, enabling us to distinguish in the text database and dictionary between hypothetical readings and secure decipherments. By using propositional logic, for example, our evaluation of the more than six readings that have been proposed for the "star war" hieroglyph, which expresses war against a given site (see Stuart, 1995; Martin, 1996; Aldana, 2005; Chinchilla Mazariegos, 
2006; Voit, 2013; also Macri \& Looper, 2003; Macri \& Vail, 2009), reveals that David Stuart's (1995, p. 313) proposal, according to which the glyph represents a logographic substitution JUB "fall” for the attested syllabic spelling ju-bu, seems to be the most promising candidate. A detailed discussion of our propositional logic can be found in section 3.2.3.

Modelled in this way, our text database and dictionary of Classic Mayan will not only represent the results of our research; in addition, both components will serve as tools for further studying Classic Maya writing and language. On the one hand, our database architecture is designed to reflect the dynamics and processuality of Maya hieroglyphic research. On the other, ongoing integration of new research results will permit us to continuously improve the quality of our data. It is also important for our database work to consider the relation between text and context: hieroglyphic inscriptions very often refer to the text-bearing object itself, including its spatial, temporal and social context. When compiling the dictionary or analysing the meaning of words, Classic Mayan texts should not be considered independently of the object on which they are recorded, nor of their temporal or spatial context. The object and its context provide non-textual information, or metadata, about the text-bearing object itself, its location, neighboring texts and associated finds, its commissioner, and its historical context as a whole. These data are highly significant for deciphering and interpreting the inscriptions, and carefully documenting them in the database is a prerequisite for successful decipherment and text interpretation (Prager, 2015).

\subsubsection{Sign Lists and Classification}

Since roughly one-third of the script's signs still cannot be read, decipherment of Classic Mayan remains a frequently discussed research topic that has generated a variety of hypotheses about possible sign readings. To address the challenge of discussing signs with no known reading, epigraphers have established different inventories that assign each graph an (alpha)numeric value (Zimmermann, 1956; Thompson, 1962; Grube, 1990). Thus, a descriptive transliteration can be given independently of the signs' (different possible) phonemic values. We also aim to employ a numeric transliteration as a basis for the digital mark-up of Maya writing.

The first step is to develop a digital inventory of Maya signs and graphs. As noted in the discussion of Classic Maya graphemics above, many graphs in the script can have several variants. Yet, to this day there is no complete inventory or classification of all graphs. Identifying and cataloguing individual graphs and allographs thus represent central challenges for our project. For this reason, we first systematically reviewed existing catalogues and, eventually, opted for a modelling approach in which each graph is recorded separately from the corresponding sign's phonemic representation. Thus, we can exactly document individual graph variants, but also establish relations to other graphs to point out common diagnostic features. Uniquely, 
our sign catalogue records signs and their graph realizations as separate entities, with each receiving catalogue numbers and URIs. As such, we can be flexible in classifying the sign-grapheme relation. Each sign can be assigned multiple functions and thus also multiple transliteration values, and each can be related to 0 - $\mathrm{n}$ graphs (Diehr et al., 2017).

\subsection{Digital Epigraphy of Classic Mayan}

For digital documentation and epigraphic analysis of the text-bearing objects, we distinguish between object documentation in RDF, representation in the sign and graph database, and linguistic analysis. This work will make use of the Java-based multi-level annotation tool ALMAH (Annotator for the Linguistic Analysis of Maya Hieroglyphs), which is currently being developed in cooperation with Cristina Vertan of the University of Hamburg. In this section, we discuss these areas of work and our central concerns when creating the virtual research environment for digitally investigating Maya writing.

\subsubsection{Documentation of Object Information}

Documenting and recording text-bearing objects is the foundation of the project's textual analysis. Consequently, the project began by designing and subsequently constructing its information technology infrastructure. As noted previously, the material form in which Classic Mayan texts are recorded, and their temporal or spatial context, provide metadata about the text-bearing object and its sociocultural context. Because these data are critical to deciphering and interpreting the inscriptions, future decipherment and text interpretation depends on carefully documenting them in the database. In addition to linking with the text database, the object database can also establish and query relationships between multiple texts and text-bearing objects. This is made possible by its ontology-based modelling and implementation in a RDFdata model. Figure 5.5 gives an overview of the data structure and shows how relations can be established between artifacts, events, dates, places, appellations, references and vocabularies. Furthermore, the database also connects to the literature database compiled in Zotero. With this feature, every unit of information recorded about the text-bearing object (such as date, events, persons, its measurements, artefact type, shape, condition, find-spot, archaeological context, etc.) can be referenced with a bibliographic citation. In this way, the user can acquire an overview of who has studied or published about a monument or has discussed a text passage (Diederichs et al., 2016). 


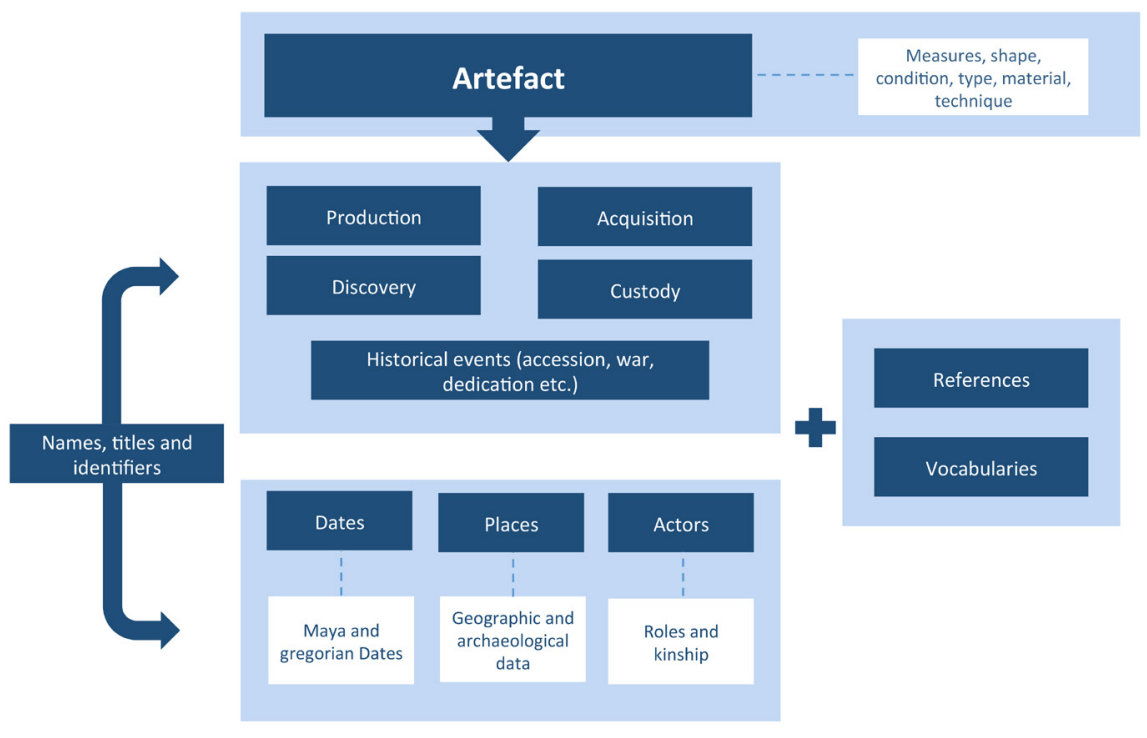

Figure 5.5: Overview of the ontology-based metadata schema for describing artefacts and their contexts

\subsubsection{Controlled Vocabularies}

The project has developed a total of 10 multilingual thesauri. In choosing appropriate entries, we prioritized normed data, such as the Getty Research Institute's Art \& Architecture Thesaurus (AAT), ${ }^{2}$ and the Getty Thesaurus of Geographic Names (TGN). ${ }^{3}$ Since the Mesoamerican, and particularly the Maya cultural spheres, are still underrepresented in the Getty thesauri, we checked a significant number of terms that had been previously employed in the literature for plausibility, comparability, and utility by for instance, consulting specific encyclopediae (e.g., Loten \& Pendergast, 1984; Gendrop, 1997; Witschey, 2016), monument corpora (e.g., Graham, 1975; Jones \& Satterthwaite, 1982), and archaeological reports (e.g., Culbert, 1993).

The resultant collection of terms was ordered according to terminological principles and modelled in the SKOS (Simple Knowledge Organization System) format in order that they could be represented in machine-readable format and

2 Getty Research Institute's Art \& Architecture Thesaurus (AAT) [http://www.getty.edu/research/ tools/vocabularies/aat/index.html].

3 Getty Thesaurus of Geographic Names (TGN) [http://www.getty.edu/research/tools/vocabularies/ tgn/index.html]. 
integrated into the metadata schema. ${ }^{4}$ The terms could thus also be simultaneously mapped onto normed data from the Getty Thesaurus, allowing the reused terms to be referenced. A special feature of SKOS is that vocabularies are represented in a concept-based manner, i.e., there are concepts with several labels, whereby one preferred label exists for each concept, to which any number of other labels can be added as alternative or hidden labels. Over the course of more than 150 years of Maya research, numerous alternative denominations for objects, persons or place names have become established in the literature, which we will document and further differentiate into preferred and alternative labels. This feature, which is useful for clarifying nomenclature and providing insight into the history of the field, also supports our work by identifying alternative or obsolete terms in the literature (Grube et al., 2016).

Developing the controlled vocabularies is highly beneficial not only to the project's own work, but also to the discipline more broadly. Until now, a multitude of terms, vocabularies, and descriptive schemas has existed in Maya epigraphy, resulting in a wide range of differentially documented text-bearing objects. At times, records exhibit relatively little agreement in application of existing terminology and are often incomplete, erroneous, imprecise, or dramatically simplified. In developing these vocabularies, the project is making a significant contribution to terminological standardization in Maya epigraphy, because we reuse terms that are already established in other scientific fields, but clearly define them for the first time and situate them in a terminological relationship to one another.

\subsubsection{Technical Infrastructure}

Data of various types are being created and stored as part of the project's workflow. Image data, metadata, and text analysis files must be managed in relation to one another within a single infrastructure for creation, storage, processing, and access regulation. We are using the virtual research environment TextGrid for these tasks. The front-end TextGrid Laboratory (TG Lab) allows files to be created and processed, in addition to facilitating fine-grained management of the rights thereto. The backend provides access to the repository (TG Rep), which stores the data in a secure environment.

The densely networked structure of the files with metadata for text-bearing objects requires appropriate storage, which we achieve by using the format RDF (Resource Description Framework) and by storing them in a graph database in the form of a triple store. An entry mask is used to record the metadata in a user-friendly manner (Figure 5.6). This HTML- and JavaScript-based tool provides the user with multiple entry aids. When utilized as a plug-in, the entry mask can be installed and directly

4 The metadata schema can be retrieved from [idiom-projekt.de/idiommask/schema.html]. 
used from the TG Lab. Examples of its supporting functions include searches in internal and external databases to establish object relations, validating entry fields, and automatically converting data formats (Neuroth, Rapp, \& Söring, 2015).

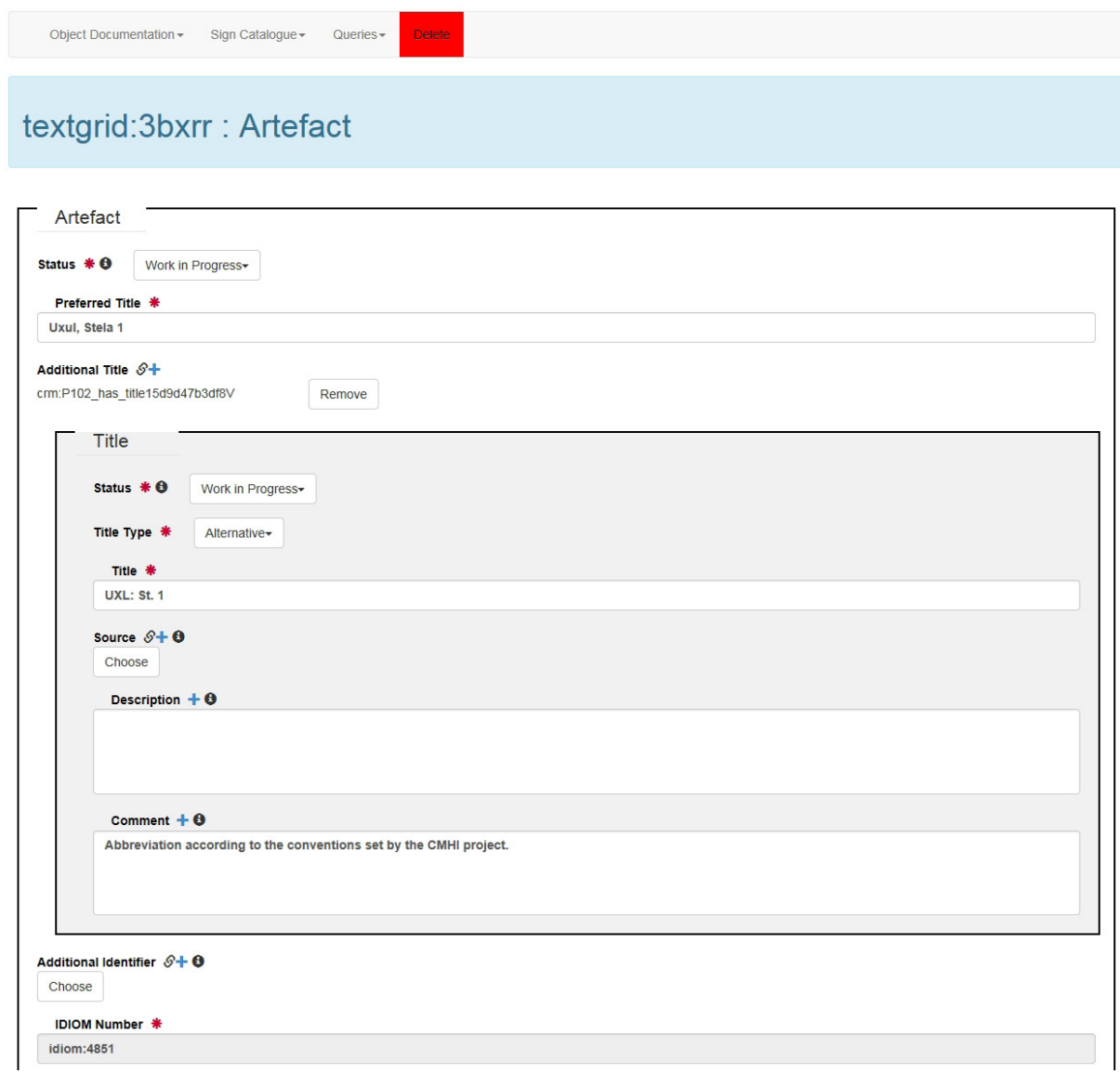

Figure 5.6: HTML and JavaScript-based entry mask to record the metadata in TextGrid

\subsubsection{Documentation of Signs and Graphs}

Documenting the original presentation of each hieroglyphic text is essential to our epigraphic work, because a linear transliteration and transcription does not display the original spellings or arrangement of the hieroglyphic inscription. Thus, texts are annotated at the level of the graph, using numeric values to represent each graph. Linguistically speaking, the graph, as the smallest graphic unit of a writing system, has not yet been assigned to a grapheme, a sign representing a phonemic value. In 
our virtual research environment, each graph is linked to the digital sign catalogue, which is a prerequisite and starting point for epigraphic text analysis (Diehr et al., 2017).

\subsubsection{Modelling Graph Variants}

The concept for the digital sign catalogue requires a data structure that enables formation of semantic relations between clearly referenced entities. As with the metadata organization for documenting object information, a data model implemented in RDF represents the optimal form of knowledge representation, and we opted to use the CIDOC Conceptual Reference Model (CRM) as the basic ontology. CIDOC CRM contains many appropriate meta-concepts that are suitable for structuring our digital sign catalogue. According to this model, a graph can be related to the functional and phonemic level of representation (modelled as the class Sign). This linking is optional, so that we can also register graphs that cannot yet be assigned to any sign.
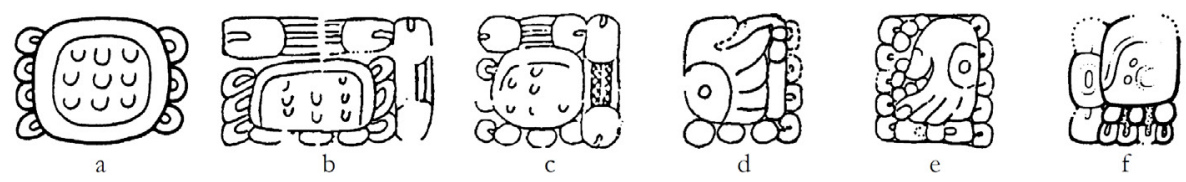

Figure 5.7: Allographic spellings of the sign 595 for the syllable no. a) Full form of 595, represented by the graph 595tv. b-c) Sign 595 in the spelling ko-ko=no=ma < kok-n-om "guardian" d) 595 used in the word TZUTZ=no=ma < tzutz-n-om "planter", e) CHOK=no=ma < chok-n-om "scatterer", f) yu-ku=no=ma $<$ yuk-n-om "shaker" (drawings by Stephen Houston, Linda Schele)

Here, a catalogue number is assigned to each sign, based on Eric Thompson's catalogue of Maya hieroglyphs (Thompson, 1962). For instance, sign number 595 represents the syllable no (Figure 5.7). When a graph has been identified as an allograph, it is assigned a graphNumber consisting of the catalogue number of the character and the abbreviation of the variation type (e.g., 595tl, where $\mathrm{tl}=$ tripartite left, meaning that the sign 595 is represented by the left-hand segment of a graph that can be cut in three vertical segments) (Diehr et al., 2017; Prager \& Gronemeyer, 2016).

\subsubsection{Modelling Multiple Sign Functions}

A feature of Maya writing is that a sign can have several readings or sign functions. The sign denoted with 528, for example, can be read as the morphograph TUN "stone”, as the morphograph CHAHUK for the name of a Maya day, or as the syllable ku (Figure 5.8). 

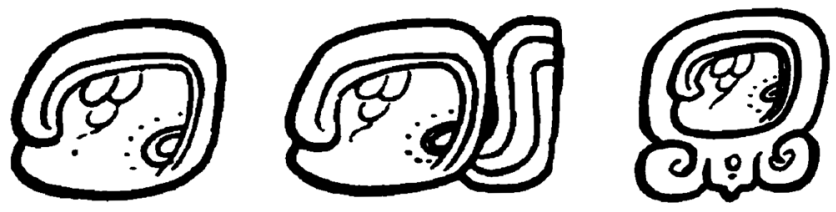

Figure 5.8: Graphs of sign 528 representing the syllable ku, the morphograph TUN "stone", and the day sign CHAHUK, the name of 19th day in the Maya calendar (drawings by M. Zender)

The graphs themselves do not indicate which reading or sign function is intended. Therefore, in our metadata schema, we consider the following possible sign functions: numerals, diacritical signs, morphographs with identified linguistic reading, morphographs with unidentified reading (in which case a meaning is assigned to the sign) and syllabic signs with identified reading. To represent them in the schema, we have modelled the class SignFunction, with the aforementioned functions as subclasses. The reading, or rather the transliteration value, is recorded as the corresponding sign function (Diehr et al., 2017).

\subsubsection{Evaluating Sign Readings}

Undeciphered signs inspire lively discourse in Maya hieroglyphic research, from which new proposals for their linguistic decipherment are constantly emerging. Examples include discussions of recent reading proposals on David Stuart's specialist blog, short articles journal Mexicon, or publications on our project's website. ${ }^{5}$ New reading hypotheses must therefore be integrated into the digital sign catalogue so that they can be analyzed in the corpus and evaluated for plausibility. In order to formally assess the quality of each linguistic decipherment, we have developed a set of criteria for sign function that are based on the linguistic context of use (e.g., part of speech, plausible text-picture reference, etc.) or lexical evidence from modern Mayan languages. The criteria for decipherment are related by means of propositional logic that produces a quality level for each reading proposal depending on its particular combination. Figure 5.9 shows the evaluation of sign 528 and its transliteration value as the morphograph TUN. To represent these evaluations in the Sign Catalogue, the class ConfidenceLevel was modelled, which is placed in relation to the class SignFunction. Therefore, a qualitative rating of the reading confidence can be obtained for each transliteration value recorded as the sign function. This rating is particularly relevant for determining the plausibility of a reading proposal within the text corpus. For example, linguistic decipherments with a particularly high level can be compared

5 David Stuarts Blog "Maya Decipherment”: [https://decipherment.wordpress.com/]; Mexicon - The Journal of Mesoamerican Studies: [www.mexicon.de]; The project's website: [www.mayadictionary.de]. 
with those with a low level. For readings with a low confidence level, new criteria for their plausibility could also be found through later research with hieroglyphic sources and the entries can then be updated in the digital Sign Catalogue (Diehr et al., 2017).

\section{Sign No. 528 with transliteration value TUN}

\begin{tabular}{|c|c|c|c|c|}
\hline \multicolumn{3}{|c|}{ selected parameter } & \multicolumn{2}{|c|}{ rules for reasoning } \\
\hline$\checkmark$ & k & complete phonetic substitution & 1 & $d \vee h \vee(k \wedge p)$ \\
\hline$\checkmark$ & c & postponed complementation [-suffix(es)] & 2 & $((o \vee y) \wedge c) \vee t$ \\
\hline$\checkmark$ & u & preconsonantal ergative pronoun & 3 & $u \wedge c \wedge(I \vee m \vee n) \wedge s \wedge i$ \\
\hline$\checkmark$ & $\mathbf{p}$ & expected part of speech & & \\
\hline$\checkmark$ & I & attested in GL languages & 4 & $(o \vee c) \wedge(1 \vee m \vee n) \wedge s$ \\
\hline$\checkmark$ & $\mathrm{m}$ & attested in other Mayan languages & 5 & $g \wedge(I \vee m \vee n) \wedge p \wedge s$ \\
\hline$\checkmark$ & $\mathrm{i}$ & semantic correspondence with graph icon & 6 & $g \wedge s \wedge p$ \\
\hline$\checkmark$ & s & semantic correspondence with context & 7 & $\mathrm{i} \wedge \mathrm{s} \wedge(u \vee y)$ \\
\hline & & $\mathbf{k}+\mathrm{c}+\mathrm{u}+\mathbf{p}+\mathrm{I}+\mathrm{m}+\mathbf{i}+\mathrm{s}$ & 8 & $\mathrm{i} \wedge \mathrm{s}$ \\
\hline
\end{tabular}

$$
d \vee h \vee(k \wedge p)=\text { level } 1
$$

Figure 5.9: Example evaluation of the transliteration value "TUN" for Sign No. 528

\subsubsection{Components for Generating a Digital Corpus}

To create a machine-readable text corpus, there must be a text that can be encoded. For Maya hieroglyphic writing, we are confronted with the problem that, due to the complexities of calligraphy and text arrangement, we cannot use a standardized font such as Unicode. Secondly, signs may fulfil several functions with various proposed readings, as explained above. Therefore, we cannot encode phonemictransliterated values, as this would preclude tagging graph variants. However, as we intend to study these variants and their usage, marking-up graphs and allographs is necessary to generate the digital corpus of Maya hieroglyphic inscriptions. Therefore, the only possibility for creating a machine-readable text is to refer to the graphic representation itself, which is where the digital Sign Catalogue comes into play: in the TEI/XML encoding process, each glyph is recorded by referring to the URI of the graph recorded in the digital Sign Catalogue. A subsequent processing step produces a human-readable text that is enriched with the transliteration values stored in the digital Sign Catalogue. On this basis, linguistic analyses can be conducted that account for the multiple functions and the various reading suggested for each sign (Diehr et al., 2017). 


\subsubsection{A TEI Schema for Digitally Documenting Maya Inscriptions}

One of the project's central tasks is to develop a metadata schema for documenting Maya hieroglyphic inscriptions. As we have outlined above, documenting the original spelling is a fundamental aspect of epigraphic work with syllabic and morphosyllabic hieroglyphic writing systems, since mere transliteration and transcription do not represent the original spelling. To digitally document Maya texts, we use XML/ TEI. In XML/TEI, texts are annotated at graph level using numeric values to represent the graphs. Within the XML/TEI document, each graph is linked to the digital sign catalogue with URIs. To encode the graphotactics of Maya hieroglyphs and represent the original spelling and graphic arrangement of each glyph block, we specified the attribute values @rend in TEI element $\langle\mathrm{g}\rangle$ to indicate the spatial relation among single graphs. Furthermore, using TEI allows us to record information concerning text structure or conservation status, graph colour, shape and location of the text field, and so on.

Our aim is to digitally represent all features of text arrangement. Thus, an important requirement for the TEI schema is that it digitally represents the semantic and topographic structure of a hieroglyphic text and its associated iconography. The schema must display the logical reading order, as well as the actual text arrangement and graph order. Topographically, this means that the schema must indicate the text's location and the position of each graph in relation to its neighbours. The semantic text structure should show how a hieroglyphic text is read and of which logical sequence it consists.

In another step, we also addressed the question of how to deal with unreadable, vague or reconstructed text passages and how to model them in the TEI schema. Our approach is to develop a text-critical analysis that can be taken into account in epigraphic and linguistic analysis of hieroglyphic inscriptions. Thus, our TEI schema also accommodates unclear or restored text passages that have been damaged or destroyed by physical, chemical, or biological influences. We also attend to text design, i.e., we characterize the inscription's design and typography, as well as the relationship between text and image: what criteria for text design may be relevant to our research questions, and what is the relationship between design and semantics? Our TEI schema therefore records characteristics such as the form of a text field, relief, framing, coloration, or font size, as well as individual hands of scribes or workshops (Maier, 2015; Diederichs et al., 2016; Diehr et al., 2017).

\subsubsection{Multi-Level, Semi-Automatic Annotation of Classic Mayan}

The TEI markup still lacks any linguistic annotation and analysis. For this, we are cooperating with Cristina Vertan to use an XML-based tool, ALMAH (Annotator for the Linguistic Analysis of Maya Hieroglyphs), originally developed for semi- 
automatic annotation of fidal, the Old Ethiopic script. ${ }^{6}$ This analysis tool will be adapted for epigraphic and linguistic analysis of Maya hieroglyphic texts to allow semi-automatic, multi-level annotation. ALMAH will allow us to create dictionary entries from analyses of hieroglyphic inscriptions. Just like the digital sign catalogue, this tool will be adaptable so that it can continually incorporate new research findings about Classic Mayan grammar and morpho-syntax. In contrast to traditional epigraphic analysis that focuses on transliterating and transcribing, this approach will include steps that not only reflect the need to achieve machine-readability in a granular and transparent way, but also increase comprehensibility of analysis in general. Transparency in analysis, accommodation of incomplete decipherments, integration of reading hypotheses and connections to the object data schema and the data contained therein: these features constitute our digital approach to not only compiling a semi-deciphered writing system and language in a dictionary, but also to deciphering them in the near future.

\subsection{Summary and Conclusion}

The subject of the project Text Database and Dictionary of Classic Mayan is an incompletely deciphered, complex writing system. The project aims to decipher it using digital tools and will describe its underlying language in a dictionary. To these ends, Maya hieroglyphic texts are being made machine-readable using XML/TEI and saved in a text database with analysis and commentary. In addition, the Classic Mayan language is represented in its original orthography in a web-based dictionary, which will allow users to compare the content with its analysis. This is a desideratum that we can also identify in the study of other ancient writing systems. The documentation of original spellings and references to the entire text has often been lacking in Egyptology, for example, where standardized representation of hieroglyphs is the norm. The digital age can easily remedy this shortcoming.

Even a glance at the epigraphic projects united in this volume indicates that Maya epigraphy is not alone in confronting the challenges presented by complex, hieroglyphic and morpho-syllabic writing systems, as exemplified by the Sinleqiunnini, OIMEA or HPM projects. However, when developing databases, most research projects in digital epigraphy do not usually face the additional difficulty of their respective writing systems and corresponding languages being only partially, or not at all, deciphered. Our goal is to use digital tools to compile and register newly classified signs in sign lists, make the texts machine-readable, discern readings, and document the Classic Mayan vocabulary in its original representation.

6 Vertan, Cristina. GeTa, a multi-level semi-automatic annotation tool for Classical Ethiopic. DOI: https://doi.org/10.5281/zenodo.160366 
The project's outcomes will ultimately include developing tools, methods and standards for digital research on ancient writing systems and for the digital humanities as a whole, in addition to producing content about the Maya script. The project's emphases on digital epigraphy, knowledge representation, database development and long-term and interoperable storage of research data, in particular, underscore the great significance of the digital humanities for such an innovative undertaking. Yet, we are also contributing to computer-based research on writing systems and developing methods and standards that will benefit other areas of research.

\section{Bibliography}

Aldana, G. (2005). Agency and the "Star War" Glyph: A Historical Reassessment of Classic Maya Astrology and Warfare. Ancient Mesoamerica, 16(2), 305-320.

Chinchilla Mazariegos, 0. (2006). A Reading for the "Earth-Star" Verb in Ancient Maya Writing (Research Reports on Ancient Maya Writing 56). Barnardsville, NC: Center for Maya Research.

Culbert, T.P. (1993). The Ceramics of Tikal-Vessels from the Burials, Caches and Problematical Deposits (Tikal Report 25A. University Museum Monograph 81). Philadelphia, PA: University of Pennsylvania Museum of Archaeology and Anthropology.

Diederichs, K., Gronemeyer, S., Prager, C., Wagner, E., Diehr, F., Brodhun, M., \& Grube, N. (2016). A Virtual Research Environment to Document and Analyze Non-alphabetic Writing Systems: A Case Study for Maya Writing. In S. Orlandi, R. Santucci, F. Mambrini, \& P.M. Liuzzo, (Eds.), Digital and Traditional Epigraphy in Context. Proceedings of the EAGLE 2016 International Conference (pp. 233-246). Roma: Sapienza Università Editrice. doi: 10.13133/978-889377-021-7

Diehr, F., Brodhun, M., Gronemeyer, S., Diederichs, K., Prager, C., Wagner, E., \& Grube, N. (2017). Modellierung eines digitalen Zeichenkatalogs für die Hieroglyphen des Klassischen Maya. In M. Eibl \& M. Gaedke (Eds.), Informatik 2017 (pp. 1185-1196). Bonn: Gesellschaft für Informatik. Retrieved from [https://dl.gi.de/handle/20.500.12116/3882], 2017/12/08.

Gendrop, P. (1997). Diccionario de Arquitectura Mesoamericana. Mexico-City: Trillas.

Graham, I. (1975). Corpus of Maya Hieroglyphic Inscriptions. Vol. 1.1: Introduction. Cambridge, MA: Peabody Museum Press.

Grube, N. (1990). Die Entwicklung der Mayaschrift: Grundlagen zur Erforschung des Wandels der Mayaschrift von der Protoklassik bis zur spanischen Eroberung (Acta Mesoamericana). Berlin: Von Flemming.

Grube, N. (1994). Observations on the History of Maya Hieroglyphic Writing. In V.M. Fields (Ed.), Seventh Palenque Round Table, 1989 (The Palenque Round Table Series) (pp. 177-186). San Francisco, CA: Pre-Columbian Art Research Institute.

Grube, N. (2001). Hieroglyphs, the Gateway to History. In N. Grube, E. Eggebrecht, \& M. Seidel (Eds.), Maya: Divine Kings of the Rain Forest (pp. 115-127). Köln: Könemann.

Grube, N. \& Prager, C.M. (2016). Vom Regenwald ins World Wide Web. In Union der deutschen Akademien der Wissenschaften (Ed.), Die Wissenschaftsakademien - Wissensspeicher für die Zukunft: Forschungsprojekte im Akademienprogramm (pp. 16-17). Berlin: Union der deutschen Akademien der Wissenschaften.

Grube, N., Prager, C., Diederichs, K., Gronemeyer, S., Wagner, E., Brodhun, M., \& Diehr, F. (2016). Annual Report for 2015. Textdatenbank und Wörterbuch des Klassischen Maya. doi: 10.20376/ IDIOM-23665556.16.pro03.en 
Houston, S.D. \& Martin, S. (2016). Through Seeing Stones: Maya Epigraphy as a Mature Discipline. Antiquity, 90(350), 443-455.

Jones, C. \& Satterthwaite, L. (1982). The Monuments and Inscriptions of Tikal-The Carved Monuments. (Tikal Report 33A. University Museum Monograph 44). Philadelphia, PA: University of Pennsylvania Museum of Archaeology and Anthropology.

Loten, H.S. \& Pendergast, D.M. (1984). A Lexicon for Maya Architecture. Toronto: Royal Ontario Museum. Retrieved from [https://archive.org/details/lexiconformayaaro0lote], 2018/02/15.

Macri, M.J. \& Looper, M. (2003). The New Catalog of Maya Hieroglyphs: The Classic Period Inscriptions (Civilization of the American Indian Series 247). Norman, OK: University of Oklahoma Press.

Macri, M.J. \& Vail, G. (2009). The New Catalogue of Maya Hieroglyphs: The Codical Texts (Civilization of the American Indian Series 264). Norman, OK: University of Oklahoma Press.

Maier, P. (2015). Ein TEl-Metadatenschema für die Auszeichnung des Klassischen Maya. Textdatenbank und Wörterbuch des Klassischen Maya. doi: 10.20376/IDIOM-23665556.15.wp003.de

Martin, S. (1996). Tikal's “Star War" Against Naranjo. In M.J. Macri \& J. McHargue (Eds.), Eighth Palenque Round Table, 1993 (Palenque Round Table Series 10) (pp. 223-236). San Francisco, CA: Pre-Columbian Art Research Institute.

Martin, S. \& Grube, N. (2008). Chronicle of the Maya Kings and Queens: Deciphering the Dynasties of the Ancient Maya ( $2^{\text {nd }}$ ed.). London: Thames \& Hudson.

Neuroth, H., Rapp, A., \& Söring, S. (Eds.). (2015). TextGrid: Von der Community - für die Community: eine virtuelle Forschungsumgebung für die Geisteswissenschaften. Glückstadt: Hülsbuch.

Prager, C.M. (2015). Das Textdatenbank- und Wörterbuchprojekt des Klassischen Maya: Möglichkeiten und Herausforderungen digitaler Epigraphik. In H. Neuroth, A. Rapp, \& S. Söring (Eds.), TextGrid: Von der Community - für die Community: Eine Virtuelle Forschungsumgebung für die Geisteswissenschaften (pp. 105-124). Glückstadt: Werner Hülsbusch.

Prager, C.M. \& Gronemeyer, S. (2016, in press). Neue Ergebnisse in der Erforschung der Graphemik und Graphetik des Klassischen Maya. Retrieved from [https://www.academia.edu/33672448/ Neue_Ergebnisse_in_der_Erforschung_der_Graphemik_und_Graphetik_des_Klassischen_ Maya], 2017/12/08.

Stuart, D. (1995). A Study of Maya Inscriptions (PhD Dissertation). Nashville, TN: Vanderbilt University.

Thompson, J.E.S. (1962). A Catalogue of Maya Hieroglyphs (The Civilization of the American Indian Series). Norman, OK: University of Oklahoma Press.

Voit, C.A. (2013). The Venus "Shell-Over-Star" Hieroglyph And Maya Warfare: An Examination Of The Interpretation Of A Mayan Symbol (MA Thesis). Detroit, MI: Wayne State University.

Wichmann, S. (2006). Mayan Historical Linguistics and Epigraphy: A New Synthesis. Annual Review of Anthropology, 35, 279-294.

Witschey, W.R.T. (Ed.). (2016). Encyclopedia of the Ancient Maya. Lanham, MD: Rowman \& Littlefield.

Zender, M. (1999). Diacritical Marks and Underspelling in the Classic Maya Script: Implications for Decipherment (MA Thesis). Calgary: Department of Archaeology, University of Calgary.

Zimmermann, G. (1956). Die Hieroglyphen der Maya-Handschriften (Abhandlungen aus dem Gebiet der Auslandskunde. Reihe B, Völkerkunde, Kunstgeschichte und Sprachen 62). Hamburg: Cram, de Gruyter \& Co. 